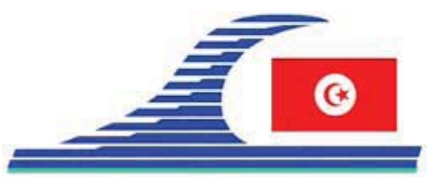

Conférence Méditerranéenne Côtière et Maritime EDITION 1, HAMMAMET, TUNISIE (2009)

Coastal and Maritime Mediterranean Conference

Disponible en ligne - http://www.paralia.fr-Available online

\title{
Contribution to the hydrodynamic design of partial breakwaters
}

\section{Bernard MOLIN ${ }^{1}$, Bruno LECUYER ${ }^{2}$, Olivier KIMMOUN ${ }^{1}$}

1. École Centrale Marseille \& IRPHE, 13451 Marseille Cedex 20, France. bernard.molin@ec-marseille.fr

2. Principia, Z.I. Athélia I, Voie Ariane, 13705 La Ciotat, France.

\begin{abstract}
:
A hydrodynamic analysis of so-called partial breakwaters ("digues partielles") is performed. It is shown that a simple rectangular shape indented with two "buckets" ("digue à baquets"), when properly dimensioned, can offer excellent performances as far as minimizing the transmission coefficient over a wide range of wave periods, with the drawback that large wave sloshing motions take place in the buckets. These shortcomings can be mitigated by adding up Jarlan walls inside the buckets, at the lee and weather sides.
\end{abstract}

Keywords: Coastal engineering - Breakwater - Hydrodynamics - Transmission coefficient - Jarlan walls

\section{Introduction}

Due to lack of space, the city of Monaco has extended over the sea, first by land reclaiming. The bordering waterdepths are now so deep that the city has been considering building housings set on jacket types of structures. These constructions would have to be protected from sea waves, by so-called "partial breakwaters". An example of such partial breakwaters is the BYBOP caisson that was installed recently at the mouth of Port Hercule (figure 1). Its shape was optimized through systematic model tests (COLMARD, 1997, see also DUCLOS et al. 2004). Quite noticeable are the slanted parts that protrude both on the up-wave and down-wave sides. The appendix on the lee-side was found to have quite a strong effect on the reduction of the transmission coefficient.

In this paper we investigate the effect of such appendices by simplifying the geometry as shown in the right-hand side of figure 1: a rectangular caisson, with two rectangular indentations at free surface level (the "buckets"). The fluid domain therefore divides into 5 rectangular sub-domains, up-wave, down-wave, below the breakwater and the two buckets. Eigen-functions expansions are used to solve the linearized diffraction problem. 

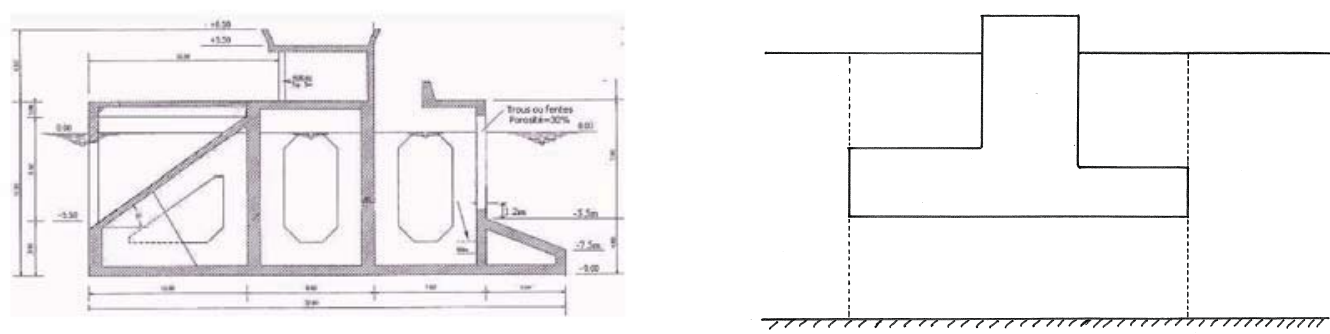

Figure 1. The BYBOP caisson (left) and the rectangular caisson indented with two "buckets" (right).

\section{Optimization analysis}

In the numerical results that follow we keep constant the waterdepth $(70 \mathrm{~m})$ and the draft $(9 \mathrm{~m})$. Figure 2 (left) shows the calculated transmission coefficient in the case of a rectangular caisson with no buckets. The width is taken successively equal to $0,20,40$ and $80 \mathrm{~m}$. The hydrodynamic performance is rather poor: at the largest width the transmission coefficient is still higher than 0.25 for wave periods beyond 10 seconds. Increasing the width does not help much. Increasing the draft is a bit more efficient hydrodynamically but not economically.
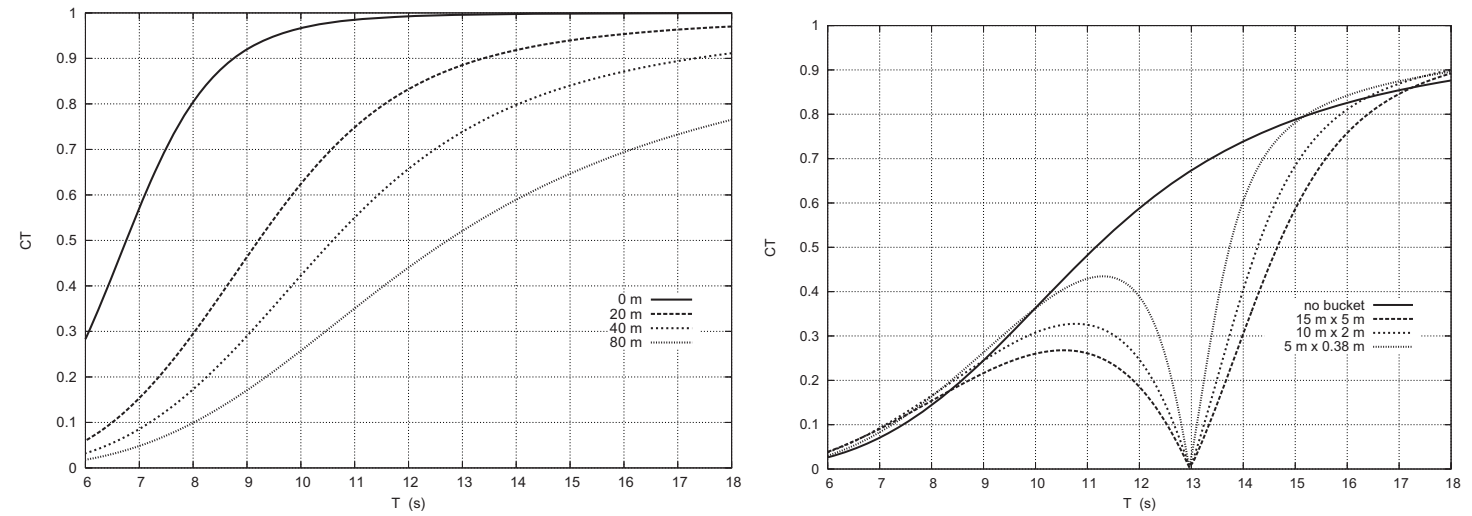

Figure 2. Transmission coefficient. Rectangular caisson (left) and caisson indented with one bucket (right).

We take the total width equal to $50 \mathrm{~m}$ and we indent the up-wave side with a bucket. Calculations are run for three dimensions of the bucket: length $15 \mathrm{~m}$, water-height $5 \mathrm{~m}$; length $10 \mathrm{~m}$, water-height $2 \mathrm{~m}$; length $5 \mathrm{~m}$, water-height $0.38 \mathrm{~m}$.

Obtained transmission coefficients $\left(C_{T}\right)$ are shown in the right-hand part of figure 2, together with the rectangular caisson case for the same $50 \mathrm{~m}$ width. With a bucket $C_{T}$ becomes nil at a wave period close to 13 seconds. The larger the bucket, the wider the trough in the curve but the same complete cancellation is obtained at 13 seconds, no matter what the size of the bucket is. 
In figure 3 we show the transmission coefficients for the following cases:

- one bucket $15 \mathrm{~m} \times 5 \mathrm{~m}$

- two identical buckets at either side $15 \mathrm{~m} \times 5 \mathrm{~m}$

- two different buckets $10 \mathrm{~m} \times 5 \mathrm{~m}$ and $15 \mathrm{~m} \times 5 \mathrm{~m}$.
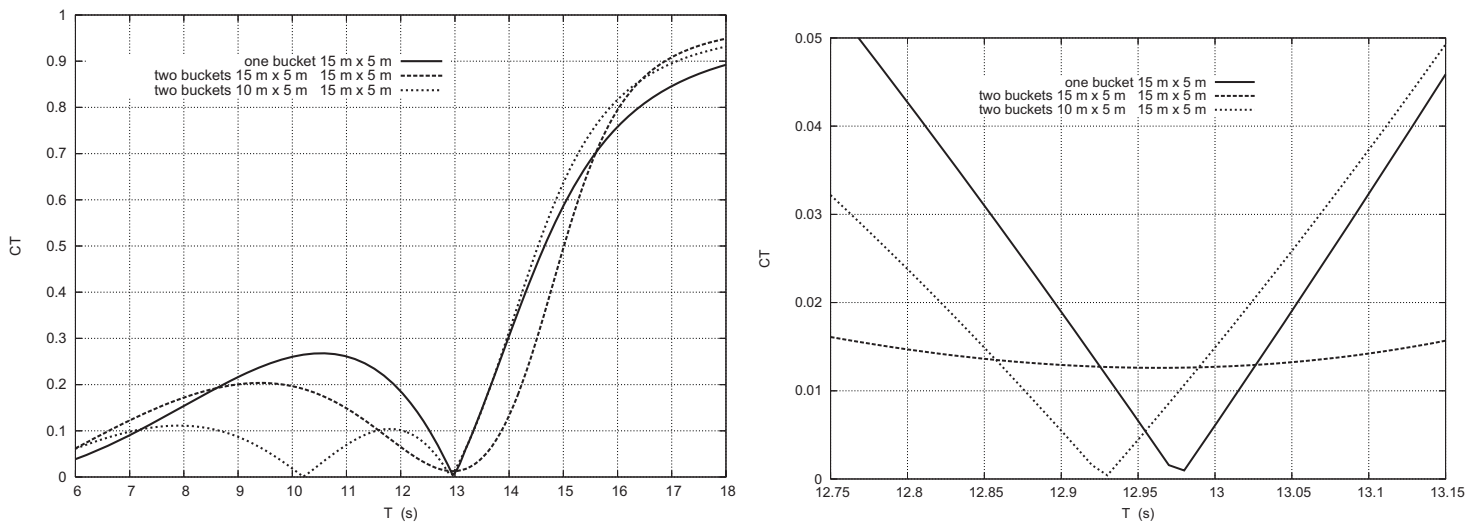

Figure 3. Transmission coefficients vs. wave period.

With the two identical buckets the trough at 13 seconds period becomes wider than with only one bucket but the minimum value is no longer zero. With two different buckets the transmission coefficient becomes nil at two wave periods, around 10.2 and 12.9 seconds in our case. [Note that, as far as the transmission and reflection coefficients are concerned, it does not matter which bucket is on the weather or lee side (KREISEL 1949). But it does make a difference for the free surface motion in the buckets. See MOLIN et al. 2009].

Finally we introduce Jarlan walls, inside the buckets. The Jarlan walls are modelled as porous plates of zero thickness where a quadratic discharge law is applied (see e.g. MOLIN, 2001).
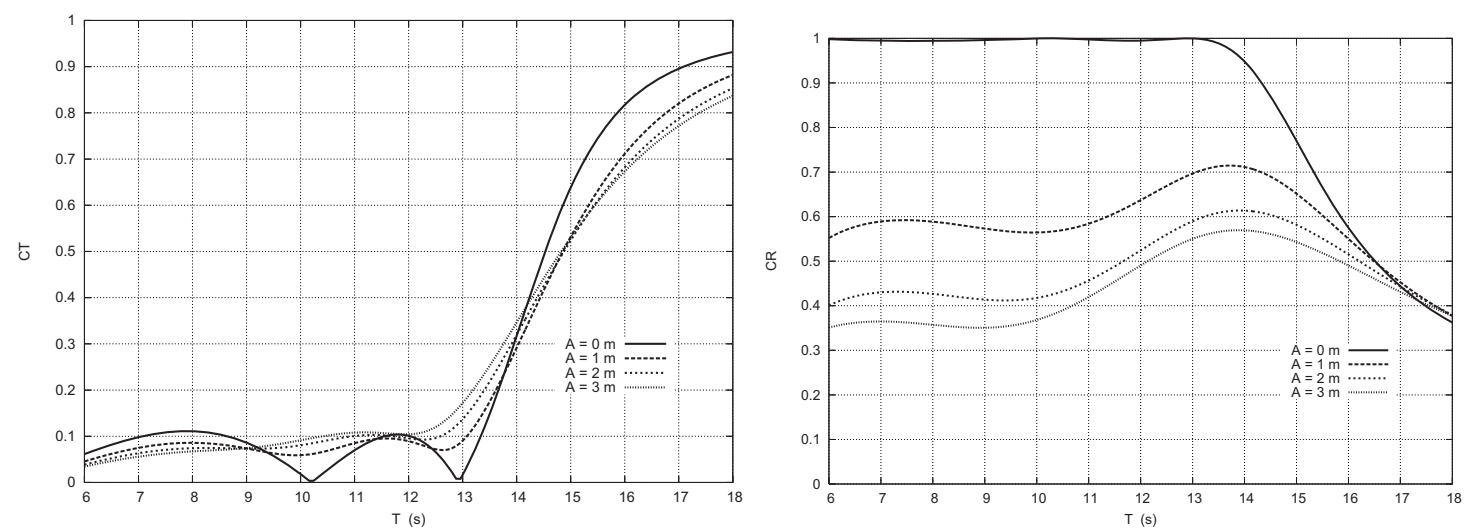

Figure 4. Buckets $10 \mathrm{~m} \times 5 \mathrm{~m} \& 15 \mathrm{~m} \times 5 \mathrm{~m}$. Total width $50 \mathrm{~m}$. With Jarlan walls. Transmission (left) and reflection (right) coefficients. 

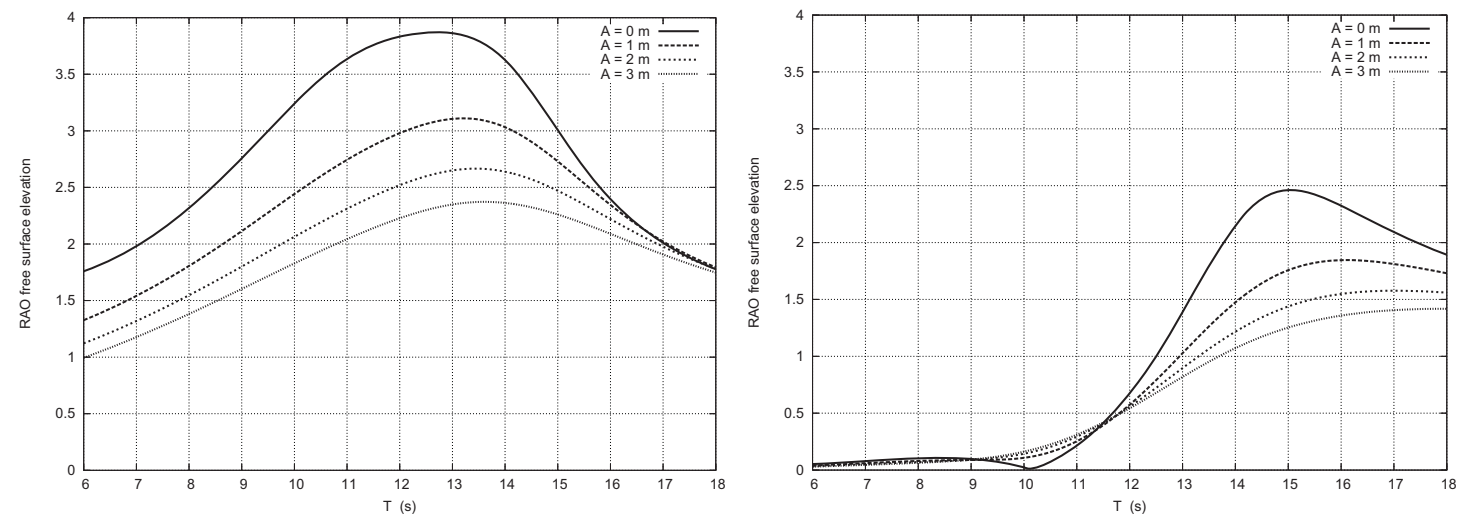

Figure 5. Buckets $10 \mathrm{~m} \times 5 \mathrm{~m} \& 15 \mathrm{~m} \times 5 \mathrm{~m}$. Total width $50 \mathrm{~m}$. With Jarlan walls. RAOs of the free surface elevation at the up-wave (left) and down-wave (right) walls.

Figures 4 and 5 show the obtained hydrodynamic performance, with the Jarlan walls inside the buckets, at $5 \mathrm{~m}$ from the inner vertical walls, in the $10 \mathrm{~m}$ x $5 \mathrm{~m}$ plus $15 \mathrm{~m}$ x 5 $\mathrm{m}$ dual bucket case. The open-area of the up-wave Jarlan wall is taken equal to $30 \%$ and the down-wave one is $20 \%$. As a result of the non-linearity of the discharge equation the transmission and reflection coefficients become amplitude dependent. It can be seen that the transmission coefficient is little dependent on the incoming wave amplitude and that the reflection coefficient can be highly reduced. This result is beneficial to mitigate wave motion on the weather side of the breakwater. Likewise the Jarlan wall on the lee side improves harbor tranquillity. Figure 5 shows the RAOs of the free surface motion inside the buckets, at the inner vertical walls.

A short experimental campaign carried out at the ECM wave flume has confirmed the results given here. More details on the hydrodynamic aspects can be found in MOLIN et al. (2009) upon which this paper is based.

\section{References}

COLMARD C. (1997). Etude des phénomènes induits par les digues partielles de type caissons montés sur pieux. $\mathrm{PhD}$ thesis, Université du Havre.

DUClOS G., JOSSET C., CLEMENT A.H., GENTAZ L., COLMARD C. (2004). Hydrodynamic efficiency of a new design of half-submerged breakwater compared to a rectangular caisson. Journal of Waterway, Port, Coastal, and Ocean Engineering, 130, pp 127-133.

KREISEL G. (1949). Surface waves. Q. Appl. Math., 7, 21-24.

MOLIN B. (2001). Numerical and physical wavetanks. Making them fit. Ship Technology Research, 48, pp 2-22.

MOLIN B., LECUYER B., REMY F. (2009). Hydrodynamic modelling of partial dikes. Proc. $24^{\text {th }}$ International Workshop on Water Waves and Floating Bodies, Zelenogorsk. 